Copyright (C) 2021 by Cherkas Global University

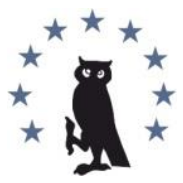

Published in the USA

Media Education (Mediaobrazovanie)

Has been issued since 2005

ISSN 1994-4160

E-ISSN 2729-8132

2021. 17(4): 702-714

DOI: $10.13187 / \mathrm{me} .2021 .4 .702$

https://me.cherkasgu.press

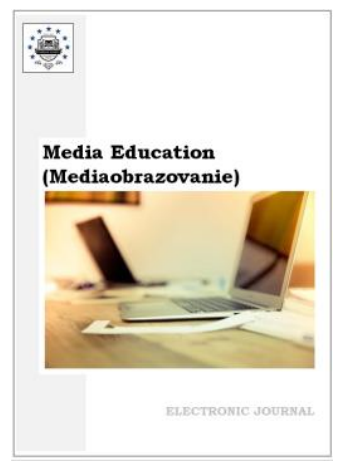

\title{
Consumption of Sexually Explicit Content through Web Series and Emerging Adults' Sexual Objectification: An Empirical Study
}

\author{
Muzammil Saeed ${ }^{a}$, *, Farahat Ali ${ }^{b}$ \\ ${ }^{a}$ University of Management and Technology, Lahore, Pakistan \\ b University of Central Punjab, Lahore, Pakistan
}

\begin{abstract}
Modern technologies play a significant role in shaping gender perception and adolescents giving more emphasize on the external rather than internal features of an individuals. This study has been designed to examine the effects of the sexually explicit content of web series on emerging adults' objectification. Survey method was applied, and data was collected from 700 undergraduate participant ages 18 to 23 studying in various public and private sector universities of Lahore, Pakistan. The study is driven by theoretical framework of uses and gratification and objectification theory. The result of the study showed that exposure of sexually explicit content through web series among male was strongly correlated with sexual objectification, dis-empathy, commenting about women's body and insulting unattractive women. Moreover, web series exposure of sexually explicit content among female was not significantly correlated with male objectification. In addition to this, web series exposure is a significant predictor of sexual objectification disempathy, commenting about women's body and insulting unattractive women among male university students. On the other hand, web series exposure of sexually explicit content is not significant predictor of sexual objectification among female university students. Hence the information acquired in this study can help in understanding the objectification decision made by males and females of this society and motivate parents to keep check on the type of contents their children are exposed to. Implication regarding media effects on gender perception and sexual objectification among male and females are discussed.

Keywords: explicit media content, media effects, sexual attitudes, sexual behavior, sexual objectification.

\section{Introduction}

Commodification of male and female body is becoming a routine in web series. The seasons of games of thrones and Spartacus remained in press for their gender subordination, high rating, and explicit sexual material (Erdem, 2017; Needham, 2017). This phenomenon has attracted the TV channels attention, and everyone tries to produce more erotic content for admiration of their work. Recently, Netflix app released a new reality television series with the name of too hot to handle is a new addition to sexually explicit content. Web series due to their length of storyline produce more powerful affect in shaping up public opinion and perception with respect to any occasion or occurring on national and world-wide level (Gillig et al., 2018). These web series are a major source of sexual information is media and this study is related to the effects of these sexual
\end{abstract}

\footnotetext{
* Corresponding author

E-mail addresses: muzammil.saeed@umt.edu.pk (M. Saeed)
} 
contents on males and females of university students of Lahore. New technologies day by day are adding up new ways to approach these sexual contents more easily and readily.

S.J. Baran (Baran, 1976) argued that many adults who are not much aware of sexuality, for them media act as a teacher. Male and female both are used as an object in media, but media objectifies women more as compared to men. In media males and females are portrayed in sexual roles, which becomes the source of entertainment and visual pleasure. This factor of objectification plays an important role in the lives of consumers, when male and female watch such type of contents in which male or female are portraying as a sex object then this affects them badly, this will change their perceptions towards opposite sex as only sex objects. These changes in behaviour of consumers have been seen in every field, whether they are in academics institutes, offices or in public.

Media contents and their characters acts as a role model for males and females, especially when they watch their favourite or famous artist on media, they try to follow their acts, without thinking that whether they are good or bad for their own health. Therefore, the aim of this study is to find out relationship between the effects of sexual contents and attitudes formation. Greater exposure leads to stronger support and acceptance. According to J.D. Brown and S.F. Newcomer (Brown, Newcomer, 1991) sexual behaviour in adolescents is neither related to number of hours of television viewing nor number of hours of sexual content viewing, but if the time in which consumer is consuming media is mostly based on sexual content, then this will affect the consumers mind and behaviour.

G.S. O'Keeffe and K. Clarke-Pearson (O'Keeffe, Pearson, 2011) found that internet is the most common form of media among males and females. On internet different social websites allow user to communicate with others. These websites contain sexual contents which are easily approachable and affects the mind of consumers. So, parents' control is must, in order to keep check on their youngster's activities. Sexual violence is also the result of these contents. When males and females watch sexual content on media and try to apply them on their life, then many cases turn out in sexual violence. Researchers conducted a survey in which they investigate that movies that show sexual violence, results in more acceptance of violence towards women (Malamuth, Check, 1981). Sexual contents in television and magazines have also been discussed, that exposure of males and females towards these contents changes their mind. Sexual health risks and negative emotions are results of these exposures (Aubrey, 2007).

Ready menu of sexual contents in every web series are now available and this led to premarital sex and wrong beliefs regarding relationships. This study additionally gives a knowledge to propose what steps must be taken in future to avoid the effects of media sexual contents.

Media contents frame an essential part of communication through which different concepts are circulated. Web series contains heavy doses of sexual content, which influence youngster's behavior. According to analysis approximately $85 \%$ of films, $82 \%$ of television contents and $59 \%$ of music videos contain sexually explicit contents (Jamieson et al., 2008). In this study only web series were selected because several studies have already been conducted on television, magazine, and internet. Web series were selected due to their immense worldwide usage and worldwide coverage.

Previously, several research studies have been published about the relationship between TV/internet/movies/music videos and sexual attitude (Braun-Courville, Rojas, 2009; Omori et al., 2011; Mikorski, Szymanski, 2017) and sexual harassment (Bernard et al., 2018; Galdi et al., 2017). No study has been done regarding web series exposure and objectification of male and female among university students. To fill this gap, current study investigates the connection between sexual web series contents and behavioural changes due to effects. Both male and female students at different universities in Lahore are covered. Objectification and Uses and Gratification theory has been applied in this research. On the basis of existing literature following objectives.

The objectives of the study are to find out the effects of sexually explicit content of web series on objectification of males and females. Moreover, the second objective is to analyse the difference of behaviours of males and females after exposure to sexual contents.

A. Bleakley, M. Hennessy, and M. Fishbein (Bleakley et al., 2011) argued that males and females of every age group are involve in sexual activities. They approach different media to seek sexual contents, so researchers try exploring the connection between seeking sexual content from different types of media and changes in behaviours. Model of Behavioural Prediction is used, and sample is collected from 810 adolescents. Male adolescents are more involved than females for seeking sexual content from pornography sites on internet, TV, movies. Researchers argue that 
consuming sexual content from media depends on the intention to seek them and these intentions operate by prescriptive pressure.

Society's early involvement in sexual activities lead to increase rate of unintentional pregnancies and infections transmitted during sexual intercourse. R.E. O'Hara, F.X. Gibbons, M. Gerrard, Z. Li, and J.D. Sargent (O’Hara et al., 2012) investigated the links and connection between early consumption of sexual content and having multiple sex partners which affects badly the sexual health of youngster in U.S. They found that movies sexual exposure increases the chances of youngsters' involvement in sexual activities by triggering them more to seek sexual content. They found that about $57 \%$ of adolescents use media for seeking sexual knowledge

In another study, C. Lou, Y. Cheng, E. Gao, X. Zuo, M.R. Emerson, and L.S. Zabin (Lou et al., 2012) found that internet, television, and movies affects the sexual behaviour of youngsters. K. Ragsdale, M.M. Bersamin, S.J. Schwartz, B.L. Zamboanga, M.R. Kerrick, and J.W. Grube (Ragsdale et al., 2014) investigated the role of four agents' which includes friends, television media, female guardian, and male guardian on the four sexual expectancies. In order to explore the associations between these four agents and sexual attitudes researcher used structural equation model. Link between music videos and social interest is found to be positive and link between music videos exposure and health related risk found to be negative. They found that our interaction with our friends will generate positive results entertainment purpose but negative for our social benefit and health.

C.L. Wright and B. Centeno (Wright, Centeno, 2018) explored the sexual contents in music by using meta-analytic analysis. First time meta-analysis is made on this topic. In past research, 26 studies show that sexual content in music affect consumer's behaviour. Music lyrics and genre are also main contributors in these behavioural changes. Consumer's age, gender, location also matter. B.A. Primack, M.A. Gold, E.B. Schwarz, and M.A. Dalton (Primack et al., 2008) selected the top music songs from famous Billboard magazine. The results of their study showed that 279 songs have sexual acts in their contents. And more shameful acts of sexualities are found in these songs, than common type of sexual acts. National songs have no sexual content, but except this majority of songs have degrading sexual contents mostly Rap songs. And songs which contain sexual contents and violence affect badly the sexual behaviours of consumers. Another study found that for males and females television programs are main source of sex education (Kinsler et al., 2019). So, it is important to take under consideration these web series.

Objectification. Objectification is defined as treating someone or giving importance to someone one the basis of their external features rather than internal beauty or characteristics. Objectification dominates all personal characters and existence of individual (Loughnan et al., 2010). A recent study suggests that girls are more affected by objectification as compared to boys. Results show that there is direct relationship between depression in girls and objectification (Grabe et al., 2016). Another study found that objectification can be categories in high and low objectification. In which females are divided in two groups in high objectification they try swimsuit and in low objectification they try sweaters. Females in sweaters get more negative comments than females in swimsuit. While negative comments also give motivation to depress ones (Gapinski et al., 2003). J.J. Muehlenkamp and R.N. Saris-Baglama (Muehlenkamp, Baglama, 2002) conducted a survey on sample of undergraduate students, on which all these negative effects (mental issues, psychological issues, eating disorders) has been tested. Because of objectification individuals are unable to detect their internal voices. Results show strong relationship between negative factors and objectification.

T.L. Tylka and M.S. Hill (Tylka, Hill, 2004) discussed the eating disorders in males and females. According to researchers, our society plays main role in this problem. Societal pressure on the psychologies of females drags them to the condition of disorder eating. Therefore, it has been focused that how these variables (body shaming, eating disorder, self-objectification) are raised by objectification. By using model researcher has conducted a survey on 460 females of college level. Findings show again direct relationship between variables and objectification.

Media Objectification. Media Objectification in this study is defined as the messages conveyed through the male actor or female actress to degrade women/male physical appearance either through sexual acts, jokes, double meaning words and the gags. C. Rollero (Rollero, 2012) found that many studies have been conducted on media objectification which shows direct and strong relationship between variables and objectification. When both male and female watch contents on media in which models are shown with perfect body, then they start to idealize them 
and for this they starve themselves to look like them, which lead them to heavy eating disorder, mental disorder, and dissatisfaction. In this study researcher focus on the same issue by conducting survey on undergraduate males and females. Results show very strong relationship. It has been also reported that male's health and happiness get affected by these type of media contents but in females along with these, they also get emotionally hurt. Male behavior towards female changes when they watch models on media because they then start to idealize them and same is the case with females.

B. Harper and M. Tiggemann (Harper, Tiggemann, 2007) investigated the role of media messages and conduct a survey on Australian females between the ages of 18 to 35, they all are expose to two conditions in first one they all can consume magazine contents, in which female sexual models are featured with male. And in second condition they are expose to magazines in which models are not featured. Results show that females who view models in magazines, report dissatisfaction with their own bodies, negative feelings, and mood swings, as compared to other females of second group. Further the role of media objectification has been also studied in males by S. Daniel and S.K. Bridges (Daniel, Bridges, 2009). They conducted a survey on college male students about their psychologies after watching models on media and the role of BMI (Body Mass Index) in their lives. Results show high level of desires in males for muscularity after watching ideal and muscular bodies on media. But in case of BMI, these variables have not affected the minds of males.

Objectification has been measured in sports contents on media (Harrison, Fredrickson, 2003). They conduct a survey on 426 females, in which they were exposed to sports magazines and sports videos (video contents of thin males and females' sports, and of non-lean females). In case of sports magazines results show feeling of satisfaction in adolescents of older ages. Self-objectification in youngsters have been seen which cause eating disorders, body shaming, body dissatisfaction and stress. In case of video contents of sports, there were two groups, one of White people and second were of other colours. White people have been affected with contents that show perfect bodies, while in case of colour people they are affected by non-lean. These results conclude that cultural difference also plays an important role in self-objectification. According to J.S. Aubrey (Aubrey, 2006) media representations of body, cause stress and factor of self-objectification in both genders. This research has been conducted on group of two years, Year 1, and Year 2, then their results are matched. Which show increase rate of self-objectification from year 1 to year 2. One thing has been noticed that objectifying sexual contents, affect males more as compared to females.

Media and attitude of Males towards Females. V.R. Padgett, J.A. Brislin Slütz, J.A. Neal (Padgett et al., 1989) found that media contents play very important role in making attitudes negative of males towards females. In this study researchers focused on the effects of violent internet material like in pornography, and attitudes of males towards females after this change in behaviour. In another study, violent attitudes of males towards females were measured (Flood, Pease, 2009). On media, violent contents play an important role in changing perceptions of individuals. According to researchers, culture and gender are main things to study in this issue because they influence a lot the perceptions of males, especially when they see on media that males are dominating females, they adopt this as their culture and shape their attitudes accordingly.

N.J. MacKay and K. Covell (MacKay, Covell, 1997) studied the women portrayal in TV advertisements in order to understand the changing attitudes of males towards females. A survey has been conducted and participants are assigned to rate advertisements or Images related to sex. Findings showed that consuming advertisements in which sex images are present, lead to higher sexual desires and negative attitudes towards females. For further understanding attitude towards Women Scale has been studied by J.T. Spence and R.L. Helmreich (Spence, Helmreich, 1972). This scale has been then measured among participants within of different regions (South as well as of non-South) and on different timing. Findings show almost same results for male attitudes towards females. Participants of south report more conservative thoughts as compared to non-southern areas. These results have also changed according to generation and culture beliefs.

C.L. Chullen, T. Adeyemi-Bello, and E. Vermeulen (Chullen et al., 2017) studied the negative and positive attitudes of males towards females. In a survey on undergraduate male and female students, negative attitude of males towards females has been recorded. More research has been conducted on university students by C. Etaugh and A. Gerson (Etaugh, Gerson, 1974) to measure their attitudes towards females. Findings show different results based on the thinking, beliefs, and education of participants. Females do not show any harsh attitudes against females. Individuals with more education show general and broad-based attitudes. Participants who have working 
mothers show different attitudes (not conservative at all) and same is the case with participants from low financial status. Another study has been conducted on university students by C. Etaugh and L. Bowen (Etaugh, Bowen, 1976) in which enrolled and non-enrolled students' attitudes towards females has been measured. Results report that non-enrolled students show more positive attitudes towards females as compared to enrolled males.

Sexually Explicit Content and Gender portrayal. A. Bleakley, P.E. Jamieson, and D. Romer (Bleakley et al., 2012) found that film stories are mostly opposite to real life, but as it is very famous media so things that films portray affect cultural values. In this study researcher focus on the sexual contents that are present in movies and the portrayal of males and females. For this purpose, data has been collected from movies. Results show that males and females role remain same throughout the research years. Increase in sexual contents has been seen, with an increasing rate of violence. One major thing has been noted that throughout these years representation of males as dominating character over females do not change.

A. Furnham and N. Bitar (Furnham, Bitar, 1993) studied British television contents, in order to study the portrayal of males and females in these contents. Data have been collected from Canada, America, Italy, and Britain television advertisements. Findings show that representation of sex roles are different and weak in Britain advertisements as compared to Italy and North America. Content analysis has been also made on males and females' portrayal in media. Females are usually characterized in media in a negative way like as a sex object. Their body has been used for different purposes for example to sell a product. Results report that females are under-represented on media, which also affects the image of females in real life and destroy them emotionally.

Another study investigated the music videos, in which 40 videos has been examined. Results show that male characters are mostly more than one in videos as compared to females. Males are usually shown as dominating characters on females and females has been shown as sex objects in contents. These results affect the consumers because when they watch such type of contents their attitudes towards females become more negative and violent (Sommers-Flanagan et al., 1993). On other hand another study studied the internet in a research along with television programs and music videos. They examined the gender portrayal and sexual attitudes. Researchers argue that portrayal of men as dominating and tough character and women as weak and sex objects has never been changed in these years. Data is collected from Dutch students (13 to 16 years old). Results show that relation between adolescents (both male and female) and rock/fast music is positive while with classical music it is negative. Whereas in case of sexual attitudes among males they approach internet to consume sexual contents that affect them badly and changes their behaviour towards females (Ter Bogt et al., 2010).

Portrayal of males and females has been also discussed in the context of video games by some studies (Burgess et al., 2007). Findings reported that females have been portrayed more as compared males and mostly in sexual way. Males are usually portrayed in action roles and more than two or three times than females. Further the effects of these negative contents have been discussed because they influence the users badly.

Uses and Gratification. Uses and Gratification theory also known as Utility Theory. This research has used this theory in exploring why individuals expose to certain type of communications which they prefer for themselves, why they understand only a little proportion of their exposure and why only remember some. According to J.G. Blumler and E. Katz (Blumler, Katz, 1974) media and selection of media merely depends on the users. These users play an important and active role in this process. They use media sources that fulfil their needs and goals at their best. R. Basilisco and K.J. Cha (Basilisco, Cha, 2015) states that media users have variety of options to satisfy and fulfil their needs. Media users watch media, perceive according to their understanding, and remember only that part of information that best satisfy their desires and pleasurable for them in some way. Therefore, this study focusses on the sexual contents of different media sources that are preferred by targeted users.

Uses and Gratification theory is applied in this study on males and females to judge why they consume sexual content and what are the effects of these contents on their behaviours. Media act as an agent that influence observer. All types of media (Television, Internet, Magazines and Mobile social media) have been studied to explore this relationship. Males and females consume media sexual content, not all these contents affect their behaviour but when they approach particular type of content that fulfil their needs than this will have greater influence on them. The sexual contents they consume have different messages like, portrayal of women as sex object, males dominate 
females by the act of sexual violence, women harassment etc., so these type of things on media shapes the mind of males towards females more negatively, which lead to the behavioural changes. People have different needs and desires depending on their age, like youngster's approach internet more as compared to other sources for fulfilment of their desires.

Objectification Theory. Objectification theory presented by B.L. Fredrickson and T.A. Roberts (Fredrickson, Roberts, 1997), in which women was described as sexual object. Theory argues that women are valued by their physical appearance and it perceived as an object piece in media. Both Researchers branded the internalization of body viewpoint as self-objectification. The habitual body monitoring, self-presentation and self-evaluation characterized by selfobjectification (McKinley, Hyde, 1996), and that relate numerous mental health problems. Two American and Australian ladies provide a significant support to objectification theory over a decade B. Moradi and Y.P. Huang (Moradi, Huang, 2008). This theory supports current study that use of web series increase self-objectification amongst youth. It is not only affecting females, but males are also under its influence. Objectification theories mostly use for women appearances that women are more effect with this term. In this study we will examine on both male and female for interesting results. Based on above literature and theoretical framework following hypotheses have been constructed. The hypotheses design for the study are as follows:

H1: There is significant relationship between web series exposure, (a) sexual objectification of females', (b) dis-empathy and commenting about females' bodies and (c) insulting of unattractive females. of males.

H2: There is significant relationship between web series exposure and female's objectification

H3: Web series exposure is a significant predictor of sexual objectification of females', Disempathy and Commenting about female's Bodies and insulting unattractive females among male university students.

H4: Web series exposure is a significant predictor of females' objectification of males among female university students.

\section{Materials and methods}

Characteristics of Participants. This is a quantitative research and survey method was used to collect the data from larger population. The number of participants in our survey was 700. Only universities of Lahore were covered for conducting survey because of budgetary and time limitations. The total population in this research study consist of both male and female students. Population is all students, and this age group was selected because it is the most active age and frequently watch different web series through internet or mobile apps including Netflix and Amazon Prime. Purposive sampling technique was applied. Purposive sampling was used because only those students were selected from different private and public universities who watch the web series and falls under the age range of 18 to 23. With the help of information impart on quantitative scale, we figure out the change in the lives of males and females because of sexual contents in web series.

Web Series Exposure. The items of this scale were constructed with the help of different studies who used television, internet, movies, and songs as exposure for the prediction of sexual behaviour and attitude in male (Braun-Courville, Rojas, 2009; Brown, L'Engle, 2009; Omori et al., 2011). The respondents were asked about the exposure to different web series which are available on internet and Netflix. Responses were taken from those students who have watched the Game of thrones, money heist, Spartacus, Shameless, Easy, The Borgias, Sex Education, The Tudors, and Masters of Sex. The reliability of scale was checked, and Cronbach alpha value was $\alpha=.71$.

Objectification. The items for the men's objectification of women questionnaire, came from statistical analysis of the data found in the P. Curran (Curran, 2004) study. In this study, factor analysis revealed three components of men's objectification of women which includes sexual objectification, dis-empathy and commenting about bodies, insulting unattractive women and media exposure. The sexual objectification factor contains 7 items, dis-empathy and commenting about bodies also contain 9 items while insulting unattractive women contain 6 items. There was total 22 items used in the study to measure the male students' objectification of female students. Moreover, to measure female objectification of men contains 25 items and adapted from L. Zolot (Zolot, 2003) study. The reliability of both scales were checked, and Cronbach alpha value for sexual objectification was $(\alpha=.82)$, dis-empathy and commenting about bodies $(\alpha=.76)$, and 
insulting unattractive women $(\alpha=.72)$. The Cronbach alpha value for female objectification of men scale was $\alpha=.86$.

Data Collection Procedure. The study data was collected between September to November 2019 and the data for this study was collected through a survey based on questionnaire that was selected as a tool for data collection. The study targeted the male and female students aged 18 to 23 years. This criterion was further divided into three categories - lower middle and upper class. All 350 males and 350 females' students responded the survey. Different private and public universities of Lahore was selected as the field of study. It is the second largest city of Pakistan and cosmopolitan in nature. Being a metropolis of the country's largest province Punjab, all the universities of Lahore cater the students from poor to rich, illiterate to highly educated families. These universities population is heterogeneous, comprising people from all regions and ethnic groups like Punjabi's, Seraiki's, Pathan's, Balochi's, Sandhi's, Kashmiris, etc.

Data Analysis. Data analysis was conducted in SPSS version 25. Pearson correlation coefficient was used for correlation analysis while hierarchical linear regression was used to check the effect of independent variable on dependent variables by controlling the different demographic variables.

\section{Discussion}

The goal of this study was to find out, through bivariate analysis, web series consumption which contains sexually explicit contents and measuring male and female objectification towards each other. Whether male and female objectification is linked with web series exposure or not.

The basis of this study was the validation by earlier researchers throughout the globe that media exposure affects male and female sexual behaviours. M. Hennessy, A. Bleakley, M. Fishbein, and A. Jordan (Hennessy et al., 2009) with the help of longitudinal study method survey reported that, the type of contents males and females consume from media always teaches them new lessons and they continuously change their behaviour according to new learning, so their exposure may not vary but their behaviour always keep changing. T.E. Ruggiero (Ruggiero, 2000) believes that uses and gratification and objectification theory provides a perfect explanation framework that adolescent seeks sexual content, and their choices of media vary, which affects their behaviour.

S. De Ridder (De Ridder, 2017) also found that youngsters are making their perceptions of having sexual relationships by watching sexual content on media. Another study argued that sex education must be incorporated in the minds of youngsters in positive and healthy way (Miller et al., 2016). Because this high level of sexual media consumption is changing sexual behaviours of adolescents in western countries. On the other hand, according to L.D. Taylor (Taylor, 2015) consumers perceive these media messages real and compare them with their real life. Whether these contents are in visual form or in verbal form the level of impact on consumer is same.

Our hypothesis that there is significant relationship among web series exposure contain sexually explicit content, sexual objectification of women, dis-empathy and commenting about women's bodies and insulting of unattractive women. The result show that there is significant relationship between these variables. Web series exposure have strong relationship with disempathy and commenting about women and moderate with insulting women and sexual objectification, moreover the study of L. Zolot (Zolot, 2003) asserts that media exposure has a strong link with sexual objectification.

Furthermore, adding to the study, the next hypothesis is that there is significant relationship between web series exposure and female objectification of men. Stating this we can mention that the results of men objectification and media exposure are not strong enough to explain that media plays a vital role in female objectification of men, similarly the results of another study explained that there are significant effects on males because of female objectification as media exposure endorse greater level of anxiety in men (Johnson et al., 2007). Reason for this is that might be men have a strong influence because they discuss the content with their friends and sometime, they watch these contents with their friends. On the other hand, female cannot openly discuss the web series content with their friends.

The next hypothesis, web series exposure is a significant predictor of sexual objectification, dis-empathy and commenting about women's bodies and insulting unattractive women behaviour among male students. The findings justify the statement because the results are significant. As J.S. Aubrey (Aubrey, 2007) states that media focuses on sexual objectification and provoke different behaviours in males. The outcome states a significant relationship as stated earlier by a previous study (Zolot, 2003). As researcher says that men do not know how much harm they are 
giving to women due to sexual objectification. As it is also discussed by K.D. Gapinski, K.D. Brownell, and M. LaFrance (Gapinski et al., 2003) who categorized females in two groups of high objectification and low objectification and concluded that media plays an important role in shaping views of males towards unattractive women.

Now coming towards female objectification of men, the two hypotheses that there is significant relationship between web series exposure and female objectification of men. Moreover, web series exposure is a significant predictor of female objectification of men. The results of both statements show that there is very weak relationship between media exposure and female objectification of men. The result shows that might be grooming of females in our society is different from men.

Limitations and Future Research. This study used a cross-sectional survey and generalizability of these results should be done with caution. Moreover, sample size of this study is also a limitation of the study because generalizing the results with this sample is not possible. Longitudinal and experiment studies could provide a better insight look to this phenomenon. This study collected the data from university student. Further studies could take the data from adolescents and older individual to check the effect of these web series on their objectification. Moreover, further studies could be performed by taking the different control variables such as sense making and perceived realism of these web series content.

\section{Results}

Hypothesis 1: There is significant relationship between media exposure, sexual objectification of women, dis-empathy and commenting about women's bodies and insulting of unattractive women. This study was done to determine whether there is a statistically significant relationship between sexual objectification, dis-empathy and commenting about bodies, insulting unattractive women and media exposure. The data were first screened for outliers and linearity using scatterplot; both rules were met. Normality was assessed with Shapiro-Wilk's test ( $p>0.05$ ).

A Pearson product moment correlation was conducted to examine the relationships between sexual objectification, dis-empathy and commenting about women bodies, insulting unattractive women and media exposure. Web series exposure was more strongly correlated to Sexual objectification $(350)=0.706, \mathrm{p}<0.001$, than dis-empathy and commenting about women's body $\mathrm{r}(350)=0.665, \mathrm{p}<0.001$ and insulting unattractive women $\mathrm{r}(350)=0.617, \mathrm{p}<0.001$. Dis-empathy and commenting about women's body was moderately correlated with insulting unattractive women $\mathrm{r}(350)$ $=0.564), p<0.001$ and strongly correlated with web series exposure $r(350)=0.739), p<0.001$. The relationship between web series exposure and insulting unattractive women was moderately correlated $\mathrm{r}(182)=0.557), \mathrm{p}<0.001$. A complete list of correlations is presented in Table 1. These findings showed that media exposure have the strongest association with dis-empathy and commenting about women bodies. Therefore, data supported the H1(a), H2(b), and H1(c).

Table 1. Correlation between Web Series exposure, sexual objectification, dis-empathy and commenting about women bodies, and insulting unattractive women among Male Students

\begin{tabular}{|c|c|c|c|c|}
\hline Variables & 1 & 2 & 3 & 4 \\
\hline $\begin{array}{l}\text { 1. Web Series Exposure } \\
\text { 2. Dis-empathy and Commenting About Women's Bodies }\end{array}$ & & $.665^{* *}$ & $\begin{array}{l}.617^{* *} \\
.564^{* * *}\end{array}$ & $\begin{array}{l}.706^{* *} \\
.739^{* *}\end{array}$ \\
\hline $\begin{array}{l}\text { 3. Insulting Unattractive Women } \\
\text { 4. Sexual Objectification }\end{array}$ & & & & $.557^{* *}$ \\
\hline
\end{tabular}

Hypothesis 2: There is significant relationship between Web Series exposure and men's objectification of women. This analysis was conducted to determine whether there is a statistically significant relationship between female objectification of men and web series exposure. The data were first screened for outliers and linearity using scatterplot; both rules were met. Normality was assessed with Shapiro-Wilk's test ( $p>0.05)$. A Pearson product moment correlation was directed to examine the relationships between web series exposure and female objectification of men female objectification of men was weakly and insignificantly correlated to web series exposure (350) $=0.127, \mathrm{p}>.05 \mathrm{H} 2$ is not supported by data. A complete list of correlations is presented in Table 2. 
Table 2. Correlation between Web Series exposure and Female's objectification of Men among Female Students

\begin{tabular}{lll}
\hline Variables & 1 & 2 \\
\hline Web Series Exposure & 1 & .127 \\
Female's Sexual Objectification of Men & .127 & 1
\end{tabular}

**. Correlation is significant at the 0.01 level (2-tailed).

Hypothesis 3: Web Series exposure is a predictor of sexual objectification, dis-empathy and commenting about women bodies, and insulting unattractive women. A hierarchical linear regression was conducted to examine web series exposure can predict sexual objectification, dis-empathy and commenting about women bodies, and insulting unattractive women. The assumption of normality has been met. An analysis of standard residuals showed that the data contained no outliers (Std. residual $\min =-.259$, std. residual $\max =2.030$ ) independence of residual errors was confirmed with a Durbin Watson test (d-2.073). Residual plots showed homoscedasticity and normality of the residuals. Web series exposure considerably predicted sexual objectification (50\%), dis-empathy and commenting about women bodies ( $55 \%$ ), and insulting unattractive women accounting for $32 \%$ change. Web series exposure significantly predicted sexual objectification $(\beta=.71, p<.001)$, the dis-Empathy and commenting about women bodies $(\beta=.74, \mathrm{p}<.05)$ and insulting unattractive women $(\beta=.56, \mathrm{p}<.05)$ among the male students. $\mathrm{H}_{3}$ is supported by data.

Table 3. Hierarchical Regression Analysis Predicting Sexual Objectification, Dis-Empathy and Commenting About Women Bodies, and Insulting Unattractive Women $(\mathrm{N}=350)$

\begin{tabular}{|c|c|c|c|c|c|c|}
\hline \multirow[b]{2}{*}{ Predictor } & \multicolumn{2}{|c|}{$\begin{array}{l}\text { Sexual } \\
\text { Objectification }\end{array}$} & \multicolumn{2}{|c|}{$\begin{array}{l}\text { Dis-Empathy and } \\
\text { Commenting About } \\
\text { Women Bodies }\end{array}$} & \multicolumn{2}{|c|}{$\begin{array}{l}\text { Insulting } \\
\text { Unattractive } \\
\text { Women }\end{array}$} \\
\hline & $\Delta \mathrm{R} 2$ & $\beta$ & $\Delta \mathrm{R} 2$ & $\beta$ & $\Delta \mathrm{R} 2$ & $\beta$ \\
\hline $\begin{array}{l}\text { Step } 1 \\
\text { Control Variables* }\end{array}$ & .08 & & .06 & & .03 & \\
\hline $\begin{array}{l}\text { Step } 2 \\
\text { Web Series Exposure } \\
\text { Total R2 }\end{array}$ & .50 & $\begin{array}{l}.71^{* * *} \\
.58^{* * *}\end{array}$ & $\begin{array}{l}.55 \\
.74^{* *} \\
.61^{* *}\end{array}$ & & $\begin{array}{l}.32 \\
.56^{* *} \\
.35^{* *}\end{array}$ & \\
\hline
\end{tabular}

Note: Control Variables ${ }^{*}=$ age, gender, education, residence, monthly family income, ${ }^{*} p<.05$, ${ }^{* *} p<.01,{ }^{* * *} \mathrm{p}<.001$

A hierarchical linear regression was conducted to examine whether web series exposure can female objectification for men. An analysis of standard residuals showed that the data contained no outliers (Std. residual $\mathrm{min}=-.259$, std. residual $\max =2.030$ ) independence of residual errors was confirmed with a Durbin -Watson test (d-2.073). Residual plots showed homoscedasticity and normality of the residuals. Media exposure insignificantly predicted female objectification for men $\mathrm{F}(6,343)=2.20, \mathrm{p}>.05$, accounting for $1 \%$ change in female objectification for men (adjusted $\mathrm{R}$ square $=.032$ ). Web series exposure insignificantly predicted the female objectification for men among the female students. $\mathrm{H}_{4}$ is supported by data.

Table 4. Hierarchical Regression Analysis Predicting Female objectification for Men $(\mathrm{N}=350)$

\begin{tabular}{llc}
\hline & \multicolumn{2}{l}{ Female objectification for Men } \\
\cline { 2 - 3 } Predictor & $\Delta \mathrm{R} 2$ & $\beta$ \\
\hline Step 1 & .05 & \\
Control Variables* & & .01 \\
Step 2 & & .12 \\
Web Series Exposure & & .06 \\
Total R2 & & \\
\hline
\end{tabular}

Note: Control Variables* $=$ age, gender, education, residence, monthly family income

${ }^{*} \mathrm{p}<.05,{ }^{* *} \mathrm{p}<.01,{ }^{* * *} \mathrm{p}<.001$ 


\section{Conclusion}

The results of this study show that exposure of sexually explicit content is related to sexual objectification of others. This study will be helpful for media educators, parents, and practitioners, so that they can educate the students about the detrimental effects of these content which is easily available on websites and on different apps. These results also suggest that we should consider consequences of the sexually explicit content available in web series.

\section{References}

Aubrey, 2006 - Aubrey, J.S. (2006). Effects of sexually objectifying media on selfobjectification and body surveillance in undergraduates: Results of a 2-year panel study. Journal of Communication. 56(2): 366-386.

Aubrey, 2007 - Aubrey, J.S. (2007). The impact of sexually objectifying media exposure on negative body emotions and sexual self-perceptions: Investigating the mediating role of body selfconsciousness. Mass Communication \& Society. 10(1): 1-23.

Baran, 1976 - Baran, S.J. (1976). Sex on TV and adolescent sexual self-image. Journal of Broadcasting \& Electronic Media. 20(1): 61-68.

Basilisco, Cha, 2015 - Basilisco, R., Cha, K.J. (2015). Uses and gratification motivation for using Facebook and the impact of Facebook usage on social capital and life satisfaction among Filipino users. International Journal of Software Engineering and Its Applications. 9(4): 181-194.

Bernard et al., 2018 - Bernard, P., Legrand, S., Klein, O. (2018). From bodies to blame: Exposure to sexually objectifying media increases tolerance toward sexual harassment. Psychology of Popular Media Culture. 7(2): 99-112.

Bleakley et al., 2011 - Bleakley, A., Hennessy, M., Fishbein, M. (2011). A model of adolescents' seeking of sexual content in their media choices. Journal of sex research. 48(4): 309-315.

Bleakley et al., 2012 - Bleakley, A., Jamieson, P.E., Romer, D. (2012). Trends of sexual and violent content by gender in top-grossing US films, 1950-2006. Journal of Adolescent Health. 51(1): 73-79.

Blumler, Katz, 1974 - Blumler, J.G., Katz, E. (1974). The uses of mass communications: Current perspectives on gratifications research. Sage Publications, Inc.

Braun-Courville, Rojas, 2009 - Braun-Courville, D.K., Rojas, M. (2009). Exposure to sexually explicit web sites and adolescent sexual attitudes and behaviors. Journal of adolescent health. 45(2): 156-162.

Brown, L'Engle, 2009 - Brown, J.D., L'Engle, K.L. (2009). X-rated: Sexual attitudes and behaviors associated with US early adolescents' exposure to sexually explicit media. Communication Research. 36(1): 129-151.

Brown, Newcomer, 1991 - Brown, J.D., Newcomer, S.F. (1991). Television viewing and adolescents' sexual behavior. Journal of homosexuality. 21(1-2): 77-91. DOI: https://doi.org/ 10.1300/Jo82v21no1_07

Burgess et al., 2007 - Burgess, M.C.R., Stermer, S.P., Burgess, S.R. (2007). Sex, lies, and video games: the portrayal of male and female characters on video game covers. Sex Roles. 57(5-6): 419-433. DOI: https://doi.org/10.1007/s11199-007-9250-0

Chullen et al., 2017 - Chullen, C.L., Adeyemi-Bello, T., Vermeulen, E. (2017). A comparative analysis of attitudes towards women as managers in the US and Netherlands. Journal of Leadership, Accountability and Ethics. 14(2): 1-19.

Curran, 2004 - Curran, P. (2004). Development of a new measure of men's objectification of women: Factor structure test retest validity. [Electronic resource]. URL: http://digitalcommons. iwu. edu/psych_honproj/13

Daniel, Bridges, 2010 - Daniel, S., Bridges, S.K. (2010). The drive for muscularity in men: Media influences and objectification theory. Body image. 7(1): 32-38. DOI: https://doi.org/ 10.1016/j.bodyim.2009.08.003

De Ridder, 2017 - De Ridder, S. (2017). Social Media and Young People's Sexualities: Values, Norms, and Battlegrounds. Social Media+ Society. 3(4): 2056305117738992.

Erdem, 2017 - Erdem, M.N. (2017). Violence and pornographic violence as a mass entertainment medium: A study on Spartacus series. In Violence and Society: Breakthroughs in Research and Practice. IGI Global: 685-703. 
Etaugh, Bowen, 1976 - Etaugh, C., Bowen, L. (1976). Attitudes toward women: comparison of enrolled and nonenrolled college students. Psychol Rep. 38(1): 229-230. DOI: https://doi.org/ 10.2466/pro.1976.38.1.229

Etaugh, Gerson, 1974 - Etaugh, C., Gerson, A. (1974). Attitudes toward Women: Some Biographical Correlates. Psychol Rep. 35(2): 701-702. https://doi.org/10.2466/pro.1974.35.2.701

Flood, Pease, 2009 - Flood, M., Pease, B. (2009). Factors influencing attitudes to violence against women. Trauma, Violence, \& Abuse. 10(2): 125-142. DOI: https://doi.org/10.1177 /1524838009334131

Fredrickson, Roberts, 1997 - Fredrickson, B.L., Roberts, T.A. (1997). Objectification theory: Toward understanding women's lived experiences and mental health risks. Psychology of women quarterly. 21(2): 173-206.

Furnham, Bitar, 1993 - Furnham, A., Bitar, N. (1993). The stereotyped portrayal of men and women in British television advertisements. Sex Roles. 29(3-4): 297-310. DOI: https://doi.org/10.1007/BFo0289940

Galdi et al., 2017 - Galdi, S., Maass, A., Cadinu, M. (2017). Defending the victim of sexual harassment: The influence of civil courage and media exposure.Psychology of Women Quarterly. 41(3): 338-351.

Gapinski et al., 2003 - Gapinski, K.D., Brownell, K.D., LaFrance, M. (2003). Body objectification and "fat talk": Effects on emotion, motivation, and cognitive performance. Sex roles. 48(9-10): 377-388.

Gillig et al., 2018 - Gillig, T.K., Rosenthal, E.L., Murphy, S.T., Folb, K.L. (2018). More than a media moment: The influence of televised storylines on viewers' attitudes toward transgender people and policies. Sex Roles. 78(7-8): 515-527.

Grabe et al., 2016 - Grabe, S., Hyde, J.S., Lindberg, S.M. (2016). Body Objectification and Depression in Adolescents: The Role of Gender, Shame, and Rumination. Psychology of Women Quarterly. 31(2): 164-175. https://doi.org/10.1111/j.1471-6402.2007.00350.x

Harper, Tiggemann, 2008 - Harper, B., Tiggemann, M. (2008). The Effect of Thin Ideal Media Images on Women's Self-Objectification, Mood, and Body Image. Sex Roles. 58(9-10): 649-657. DOI: https://doi.org/10.1007/s11199-007-9379-x

Harrison, Fredrickson, 2003 - Harrison, K., Fredrickson, B.L. (2003). Women's sports media, self-objectification, and mental health in black and white adolescent females. Journal of Communication. 53(2): 216-232. DOI: https://doi.org/10.1111/j.1460-2466.2003.tbo2587.x

Hennessy et al., 2009 - Hennessy, M., Bleakley, A., Fishbein, M., Jordan, A. (2009). Estimating the longitudinal association between adolescent sexual behavior and exposure to sexual media content. Journal of sex research. 46(6): 586-596. DOI: https://doi.org/10.1080/002244 90902898736

Jamieson et al., 2008 - Jamieson, P.E., More, E., Lee, S.S., Busse, P., Romer, D. (2008). It matters what young people watch. In Romer, D., Jamieson, P. (eds.), The Changing Portrayal of Adolescents in the Media Since 1950. Routledge: 105-131.

Johnson et al., 2007 - Johnson, P.J., McCreary, D.R., Mills, J.S. (2007). Effects of exposure to objectified male and female media images on men's psychological well-being. Psychology of Men \& Masculinity. 8(2): 95-102.

Kinsler et al., 2019 - Kinsler, J.J., Glik, D., Castro Buffington, S. de, Malan, H., Nadjat-Haiem, C., Wainwright, N., Papp-Green, M. (2019). A content analysis of how sexual behavior and reproductive health are being portrayed on primetime television shows being watched by teens and young adults. Health communication. 34(6): 644-651. DOI: https://doi.org/10.1080/1041023 6.2018.1431020

Lou et al., 2012 - Lou, C., Cheng, Y., Gao, E., Zuo, X., Emerson, M.R., Zabin, L.S. (2012). Media's contribution to sexual knowledge, attitudes, and behaviors for adolescents and young adults in three Asian cities. The Journal of adolescent health: official publication of the Society for Adolescent Medicine. 50(3S): S26-36. DOI: https://doi.org/10.1016/j.jadohealth.2011.12.009

Loughnan et al., 2010 - Loughnan, S., Haslam, N., Murnane, T., Vaes, J., Reynolds, C., Suitner, C. (2010). Objectification leads to depersonalization: The denial of mind and moral concern to objectified others. European Journal of Social Psychology. 40(5): 709-717.

MacKay, Covell, 1997 - MacKay, N.J., Covell, K. (1997). The impact of women in advertisements on attitudes toward women. Sex roles. 36(9-10): 573-583. 
Malamuth, Check, 1981 - Malamuth, N.M., Check, J.V. (1981). The effects of mass media exposure on acceptance of violence against women: A field experiment. Journal of Research in Personality. 15(4): 436-446. DOI: https://doi.org/10.1016/0092-6566(81)90040-4

McKinley, Hyde, 1996 - McKinley, N.M., Hyde, J.S. (1996). The objectified body consciousness scale: Development and validation. Psychology of women quarterly. 20(2): 181-215.

Mikorski, Szymanski, 2017 - Mikorski, R., Szymanski, D.M. (2017). Masculine norms, peer group, pornography, Facebook, and men's sexual objectification of women. Psychology of Men \& Masculinity. 18(4): 257-267.

Miller et al., 2016 - Miller, A. N., Nalugya, E., Gabolya, C., Lagot, S., Mulwanya, R., Kiva, J. ... Chibita, M. (2016). The association between Ugandan adolescents' viewing of specific television genres and sex-related normative beliefs and behaviours. Communicatio. 42(2): 221-237. DOI: https://doi.org/10.1080/02500167.2016.1187187

Moradi, Huang, 2008 - Moradi, B., Huang, Y.P. (2008). Objectification theory and psychology of women: A decade of advances and future directions. Psychology of women quarterly. 32(4): 377-398.

Muehlenkamp, Saris-Baglama, 2002 - Muehlenkamp, J.J., Saris-Baglama, R.N. (2002). Self-Objectification and Its Psychological Outcomes for College Women. Psychology of Women Quarterly. 26(4): 371-379. DOI: https://doi.org/10.1111/1471-6402.to1-1-00076

Needham, 2017 - Needham, J.K. (2017). Visual misogyny: An analysis of female sexual objectification in game of thrones. Femspec. 17(2): 3-19.

O'Hara et al., 2012 - O'Hara, R.E., Gibbons, F.X., Gerrard, M., Li, Z., Sargent, J.D. (2012). Greater exposure to sexual content in popular movies predicts earlier sexual debut and increased sexual risk taking. Psychological science. 23(9): 984-993. DOI: https://doi.org/10.1177/ 0956797611435529

O'Keeffe, Clarke-Pearson, 2011 - O'Keeffe, G.S., Clarke-Pearson, K. (2011). The impact of social media on children, adolescents, and families. Pediatrics. 127(4): 800-804. DOI: https://doi.org/10.1542/peds.2011-0054

Omori et al., 2011 - Omori, K., Zhang, Y.B., Allen, M., Ota, H., Imamura, M. (2011). Japanese college students' media exposure to sexually explicit materials, perceptions of women, and sexually permissive attitudes. Journal of Intercultural Communication Research. 40(2): 93-110.

Padgett et al., 1989 - Padgett, V.R., Brislin-Slütz, J.A., Neal, J. A. (1989). Pornography, erotica, and attitudes toward women: The effects of repeated exposure. Journal of sex research. 26(4): 479-491. https://doi.org/10.1080/00224498909551529

Primack et al., 2008 - Primack, B.A., Gold, M.A., Schwarz, E.B., Dalton, M.A. (2008). Degrading and non-degrading sex in popular music: a content analysis. Public Health Rep. 123(5): 593-60o. https://doi.org/10.1177/003335490812300509

Ragsdale et al., 2014 - Ragsdale, K., Bersamin, M.M., Schwartz, S.J., Zamboanga, B.L., Kerrick, M.R., Grube, J.W. (2014). Development of sexual expectancies among adolescents: Contributions by parents, peers and the media. Journal of sex research. 51(5): 551-560. DOI: https://doi.org/10.1080/00224499.2012.753025

Rollero, 2013 - Rollero, C. (2013). Men and women facing objectification: The effects of media models on well-being, self-esteem and ambivalent sexism. Revista de Psicología Social. 28(3): 373-382. DOI: https://doi.org/10.1174/021347413807719166

Ruggiero, 2000 - Ruggiero, T.E. (2000). Uses and gratifications theory in the 21st century. Mass communication \& society. 3(1): 3-37.

Sommers-Flanagan et al., 1993 - Sommers-Flanagan, R., Sommers-Flanagan, J., Davis, B. (1993). What's happening on music television? A gender role content analysis. Sex roles. 28(11-12): 745-753.

Spence, Helmreich, 1972 - Spence, J.T., Helmreich, R.L. (1972). The Attitudes Toward Women Scale: An objective instrument to measure attitudes toward the rights and roles of women in contemporary society. American Psychological Association.

Taylor, 2015 - Taylor, L.D. (2015). Men's sexual selectivity, romantic confidence, and gender ratios in the media. The Journal of Men's Studies. 23(1): 107-113. DOI: https://doi.org/10.1177/ 1060826514561987

Ter Bogt, 2010 - Ter Bogt, T.F., Engels, R.C., Bogers, S., Kloosterman, M. (2010). "Shake it baby, shake it": Media preferences, sexual attitudes and gender stereotypes among adolescents. Sex roles. 63(11-12): 844-859. 
Tylka, Hill, 2004 - Tylka, T.L., Hill, M.S. (2004). Objectification theory as it relates to disordered eating among college women. Sex Roles. 51(11-12): 719-730. DOI: https://doi.org/ 10.1007/s11199-004-0721-2

Wright, Centeno, 2018 - Wright, C.L., Centeno, B. (2018). Sexual content in music and its relation to sexual attitudes and behaviors among consumers: a meta-analytic review. Communication Quarterly. 46(4): 1-21. DOI: https://doi.org/10.1080/01463373.2018.1437055

Zolot, 2003 - Zolot, L. (2003). The development of a measure of men's objectification of women (Honors thesis). [Electronic resource]. URL: https://digitalcommons.iwu.edu 